\title{
Pharmacokinetic Parameter Sequence Number
}

National Cancer Institute

\section{Source}

National Cancer Institute. Pharmacokinetic Parameter Sequence Number. NCI

Thesaurus. Code C87985.

A number that identifies the ordering relations (in time, space, etc.) in a set of pharmacokinetic parameters. 